\title{
Mechanical properties of 316 L stainless steel samples fabricated by selective laser melting and comparison with other manufacturing methods
}

\author{
A. Sazgar ${ }^{*}$, V. Gholizadeh ${ }^{2}$, J. Sherafati ${ }^{2}$ \\ ${ }^{I}$ Nuclear Fuel Cycle Research School, Nuclear Science and Technology Research Institute, AEOI, P.O. Box: 11365-8486, Tehran-Iran. \\ ${ }^{2}$ Researcher of AEOI, Tehran - Iran.
}

\begin{abstract}
Selective laser melting (SLM) is an additive manufacturing technique in which a laser beam with a high energy density is used to melt a metal powder substrate. Although this technique has several advantages, including the possibility of fabricating complex metal components quickly, there are concerns about the mechanical properties of the parts produced by the SLM method. This is study aims to ensure the achievement of acceptable mechanical properties including yield stress, tensile strength, and elongation percentage compared to conventional manufacturing methods. For this purpose, samples of 316L stainless steel were printed using the SLM machine. These samples and samples of annealed 316L bar were tested under same conditions and by the same equipment. Despite the large differences in microscopic structure, no significant differences were observed in mechanical properties. Also, the obtained results were compared with the results related to the sample made by the DLD additive manufacturing method, which is similar to SLM in terms of energy source and raw materials. The result represents that the mechanical strength and microhardness of the sample produced by the SLM technique are higher than the other samples, and the elongation percentage is within the desirable range. The yield stress, tensile strength, and elongation are respectively 595Mpa, 696Mpa, and $34.5 \%$, all of which are within the acceptable range required by the standards for such samples. The investigation of the microstructure shows a complete austenitic cellular structure without considerable solidification defects. Overall, the SLM additive manufacturing is a reliable process to produce $316 \mathrm{~L}$ stainless steel parts in terms of mechanical properties.
\end{abstract}

Keywords: Additive manufacturing, Selective laser melting (SLM), 316L Stainless steel

\section{INTRODUCTION}

The most important factor affecting the mechanical properties of metal parts is the existing microstructure. In general, the structure of alloys results from a combination of chemical composition, manufacturing process, and heat treatment. Additive manufacturing is a relatively new process that has many advantages in the rapid design and manufacture of parts and has attracted the attention of many industries. There are different technologies for 3D printing, each of which has its own advantages and disadvantages, and with each of these technologies, other materials can be printed. Additive manufacturing (AM) is an approach in which a part is manufactured layer by layer from the data of a 3D model. With the development of high-energy beams, it becomes possible to manufacture metal parts with high performance. Selective Laser Melting (SLM) is the most studied laser-based additive manufacturing process for metals and alloys. Data is provided

${ }^{*}$ Coressponding Author: asazgar@aeoi.org.ir 
from a CAD model during the SLM process, which is then sliced into thin layers. Each sliced layer is further developed with the appropriate scan paths. A laser beam selectively scans and melts the powders that are previously applied on the substrate through the scanner mirrors, according to the developed scan paths. After a layer is finished, the building platform is lowered by an amount equal to the layer thickness, and a new layer of powders is spread. The process repeats until the completion of the whole part [1]. Figure 1 shows a schematic layout of the SLM process [2].

To date, the SLM process can fabricate metallic parts from different material powders, such as titanium alloys [3,4], nickel-based superalloys [5, 6], aluminum alloys [7, 8, 9], and stainless steels [10, 11]. 316L austenitic stainless steel has a special place in various industries due to its characteristics and applications. Much research has been done on the microstructure and mechanical properties of 316L samples produced by the SLM method. Some of these studies have investigated the effect of different properties of the powders used, process parameters, and sample orientation on the produced part's density, mechanical properties, and microscopic structure. Liverani et al. [12] investigated the effect of laser power, hatch distance, and part orientation on the tensile properties and fatigue of $316 \mathrm{~L}$ stainless steel. Larimian et al. [13] studied the microscopic structure, mechanical properties, and density of 316L stainless steel under the influence of various energy densities and laser surface scanning strategies. Liu et al. [14] investigated the effect of laser scanning speed on the mechanical properties and microscopic structure of 316L stainless steel. According to the results of this study, increasing the scanning speed in the range of 800 to 1000 $\mathrm{mm} / \mathrm{s}$ increases the strength and reduces the ductility. Irregular melting pools with multiple boundaries were observed at high scanning speed. The observed melting pool boundaries at high scanning speed increased the probability of brittle feature fracture. In a study by Cherry et al. [15], the effect of SLM process variables on the porosity and microscopic structure of a sample made of $316 \mathrm{~L}$ stainless steel was investigated, and an optimal value for energy density was reported. Shi et al. [16] have studied the quality of a sample made from very fine $316 \mathrm{~L}$ steel powders with a high layer thickness $(250 \mu \mathrm{m})$. Miranda et al. [17] have sharply attempted to provide a model for predicting the physical and mechanical properties of $316 \mathrm{~L}$ stainless steel produced by selective laser melting.

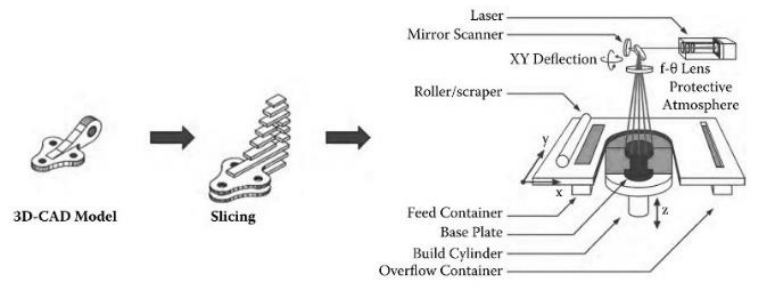

Fig. 1. Schematic diagram of the SLM process [2]

In this research, first, samples with optimized parameters are manufactured in the SLM device. Then the mechanical properties of the printed models are measured using a uniaxial tensile test. A sample of 316L stainless steel rolled bar is tested with the same equipment and under similar conditions to compare the mechanical properties. The microscopic structure of these samples is also examined using a light microscope and a scanning electron microscope (SEM-TEM). Finally, the above results are compared with the results obtained from the sample produced by the DLD ${ }^{1}$ additive manufacturing method extracted from the research of Sklyar et al. [18]. In the DLD method,

\footnotetext{
${ }^{1}$ Direct Laser Deposition
} 
like SLM, metal powder is used as raw material, and a laser beam is used as an energy source; therefore, it is comparable to the SLM method in terms of solidified structure and mechanical properties. In the DLD method, metal powder is injected directly into the molten pool. In contrast, the laser beam is concentrated on a powder bed in the SLM method and melts a layer of the defined three-dimensional model. In the end, the results obtained from the article will be presented.

\section{MATERIALS AND RESEARCH METHODS}

The powder used in this study is made of $316 \mathrm{~L}$ stainless steel, which is produced by the gas atomization method, and its particle size is $15-53$ microns. The SEM image of 316L stainless steel powder used in this research and the dimensions of some particles are shown in Figure 2a. Figure 2b shows the particle size distribution histogram. As shown in Figure 1, the powder particles are spherical. An SLM device with a 500-watt Yb fiber laser source was employed to manufacture the samples. The feedstock powder was first dehumidified in a vacuum oven at a pressure of about 0.2 atmospheres and a temperature of 100 degrees for 6 hours.

At the manufacturing time, nitrogen as the neutral gas was used, and the oxygen content inside the chamber was less than $1000 \mathrm{ppm}$. Materialise Magics and EPHatch soft wares did direction of the workpiece and process parameters. The Stripe Hatch Style was used to scan the laser during part production.
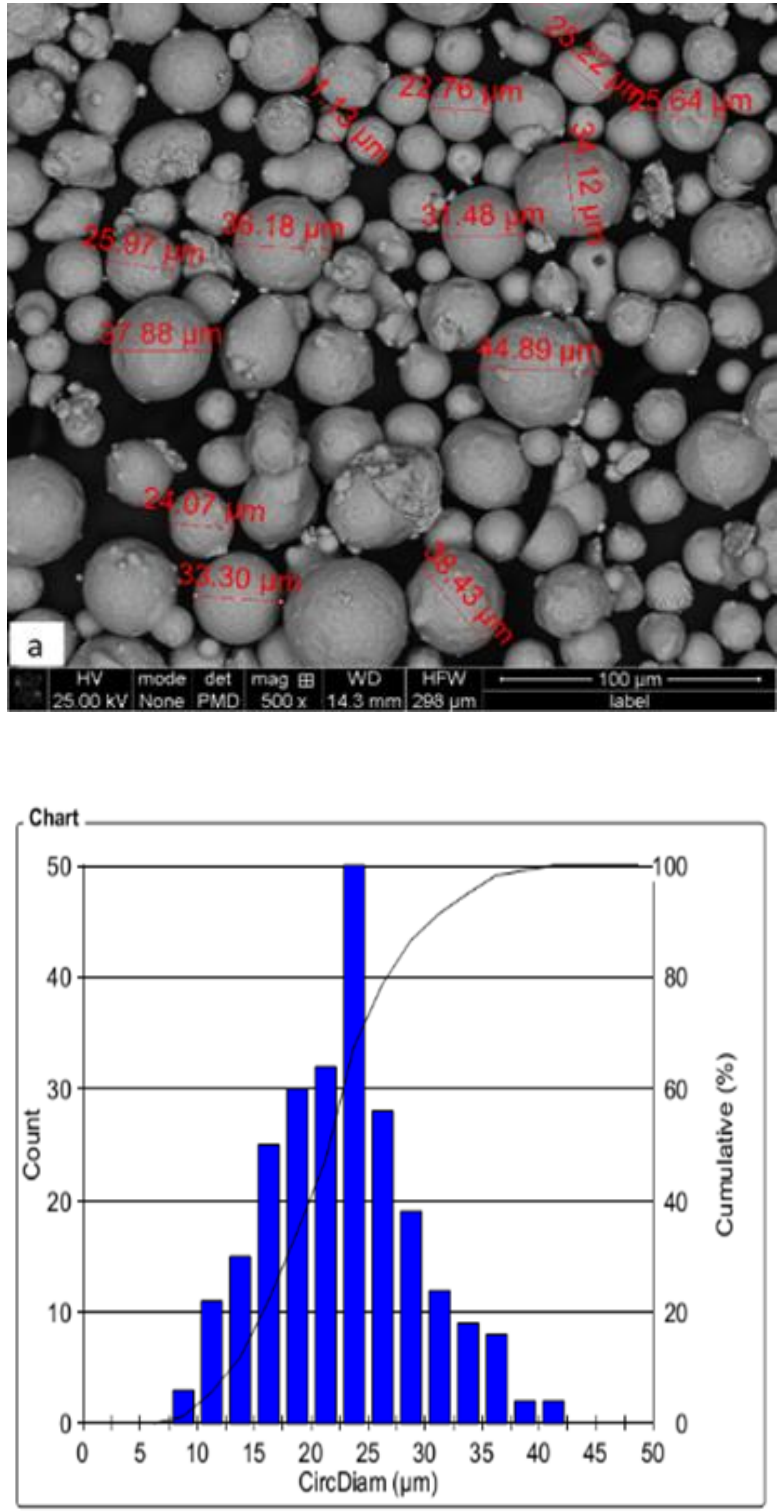

Fig. 2. (a) SEM image and (b) Particle size distribution of $316 \mathrm{~L}$ stainless steel powder

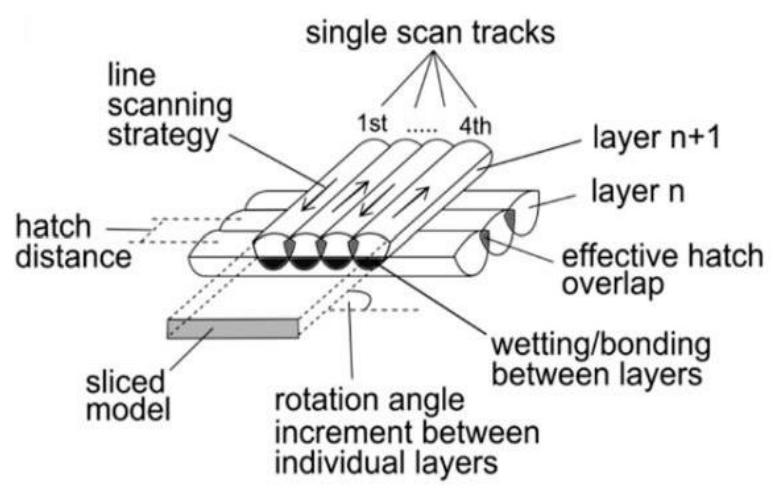

Fig. 3. Schematic of the scanning system and how layers are formed in an SLM 3D printer [19]. 
Table 1

The main parameters of SLM 3D printers in this research

\begin{tabular}{ccccc}
\hline $\begin{array}{c}\text { Oxygen } \\
\text { Content }\end{array}$ & $\begin{array}{c}\text { Protect } \\
\text { ive Gas }\end{array}$ & $\begin{array}{c}\text { Substrate } \\
\text { Temperature } \\
\mathrm{C})\end{array}$ & $\begin{array}{c}\text { Scan } \\
\text { Speed } \\
(\mathrm{mm} / \mathrm{s})\end{array}$ & $\begin{array}{c}\text { Laser } \\
\text { Powe } \\
\mathrm{r}(\mathrm{W})\end{array}$ \\
\hline $\begin{array}{c}<1000 \mathrm{pp} \\
\mathrm{m}\end{array}$ & $\mathrm{N} 2$ & 60 & 700 & 220 \\
\hline
\end{tabular}

The Hatch Distance was $0.12 \mathrm{~mm}$. Figure 3 shows the schematic of the variables related to the laser scan pattern. Also, the main process variables are given in Table 1. These parameters are the optimal values for the SLM device, and $316 \mathrm{~L}$ stainless steel powder used in this study that has already been obtained in various experiments.

Samples were designed in $13 \times 75 \times 13 \mathrm{~mm}$ dimensions and made by the SLM machine, as shown in Figure 4. Then, samples were separated from the platform by the EDM machine. The sample's chemical composition was performed using the Atomic Emission Spectroscopy (AES) method based on the ASTM E1010-16 standard. The tensile samples along the length of the specimens, perpendicular to the print direction, were made of the printed pieces under Standard ASTM A370 shown in Figure 5. The tensile test of the samples was performed with the GOTECHTCS 2000 universal machine at a temperature of 20 ${ }^{\circ} \mathrm{C}$ and a tensile speed of $0.5 \mathrm{~mm} / \mathrm{min}$.

Metallographic samples were prepared to examine the microscopic structure in two directions parallel to the print direction and perpendicular to the print direction. Preparation of metallographic samples was done in several stages by sanding and polishing operations. For sanding of samples, several sandpapers from rough to soft sand were used, and the final sanding was performed using 2500 sandpaper. Then, a 3-micron diamond paste was used for final polishing. After final polishing, the samples were electro-etched using 60\% nitric acid solution at a voltage of $1.5 \mathrm{~V}$ for 30 to 40 seconds. The microscopic structure of the samples was examined using Olympus 51BX light microscope and scanning electron microscope (SEM). Fisher's ferrite scope was used to investigate the possibility of the ferrite phase in the microstructure.

The microhardness test was performed according to ASTM E384 standard by Vickers method with a force of $500 \mathrm{~g}$.

As a comparison reference sample, metallographic, tensile, and hardness tests were performed on a sample of 316L worked steel with a diameter of $50 \mathrm{~mm}$.

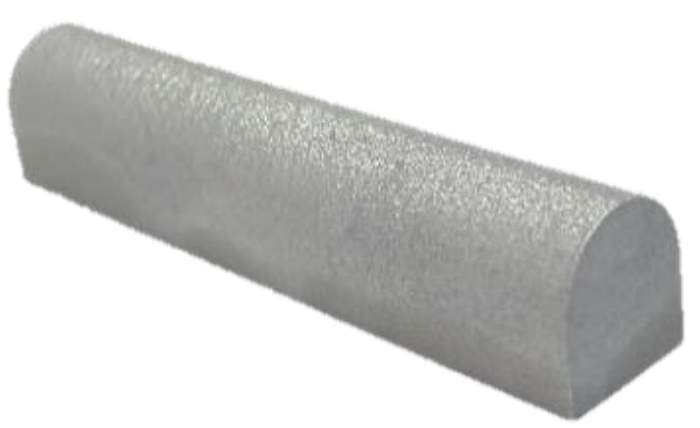

Fig. 4. Sample made with SLM 3D printer

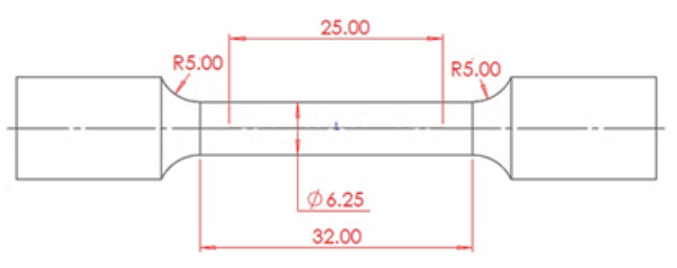

Fig. 5. Tensile test specimen dimensions (dimensions in millimeters).

Table 2

Weight percentage (wt. \%) of chemical composition of $316 \mathrm{~L}$ stainless steel powder and samples tested.

\begin{tabular}{ccccc} 
element & $\begin{array}{c}316 \mathrm{~L} \\
\text { powder }\end{array}$ & $\begin{array}{c}\text { SLM } \\
\text { sample }\end{array}$ & $\begin{array}{c}\text { rolled } \\
\text { sample }\end{array}$ & $\begin{array}{c}\text { DLD } \\
\text { sample[18] }\end{array}$ \\
\hline $\mathrm{P}$ & $<0.01$ & 0.03 & 0.034 & - \\
$\mathrm{S}$ & $<0.01$ & 0.006 & 0.016 & - \\
$\mathrm{Mo}$ & 3.0 & 2.44 & 2.07 & 3.5 \\
$\mathrm{Ni}$ & 11.0 & 11.06 & 13.61 & 12.0 \\
$\mathrm{Cr}$ & 18.6 & 17.15 & 16.5 & 16.4 \\
$\mathrm{Si}$ & 0.5 & 0.74 & 0.29 & 0.2 \\
$\mathrm{Mn}$ & 1.2 & 1.16 & 1.79 & - \\
$\mathrm{C}$ & $<0.03$ & 0.03 & 0.03 & - \\
\hline
\end{tabular}




\section{A. Sample made with SLM 3D printer}

The microscopic images of the cross-section of the sample made using the SLM 3D printer are given in figure 6. These images, taken using a light microscope and a scanning electron microscope before and after etching, show some defects in the specimens as well as the solidification structure at different magnifications. Defects such as unmelted powder particles and cavities due to improper process variables are common in samples made by SLM. Figure 5 shows these defects well with two high and low magnifications. Figure 7 shows the light microscope image of the sample without etching. Unmelted powder particles in the structure were observed to a very small extent in microscopic images. Examination of the sample using a scanning electron microscope shows not much cavity and porosity in the structure. The amount of these defects observed in the sample produced with SLM is too low to be considered. The soundless structure is because of the proper selection of the main process parameters such as laser power and scanning speed.

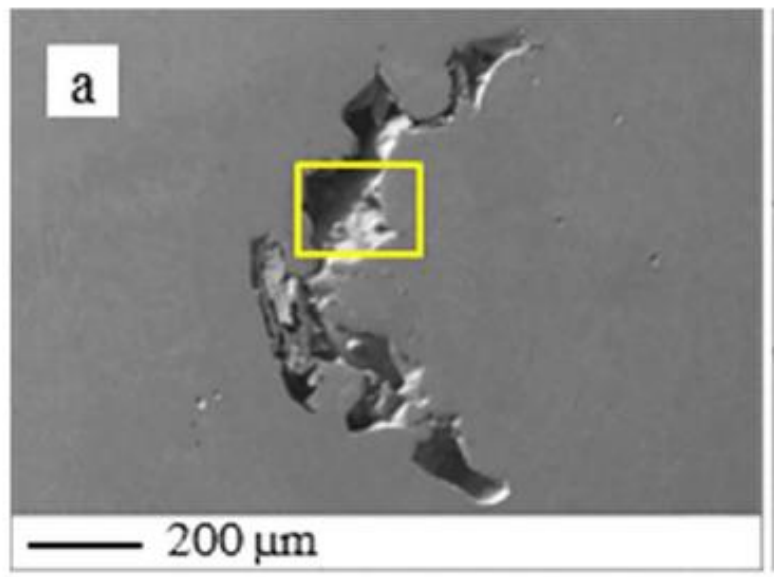

Fig. 6. SEM image of 316L stainless steel powder incomplete melting; (a) Low magnification

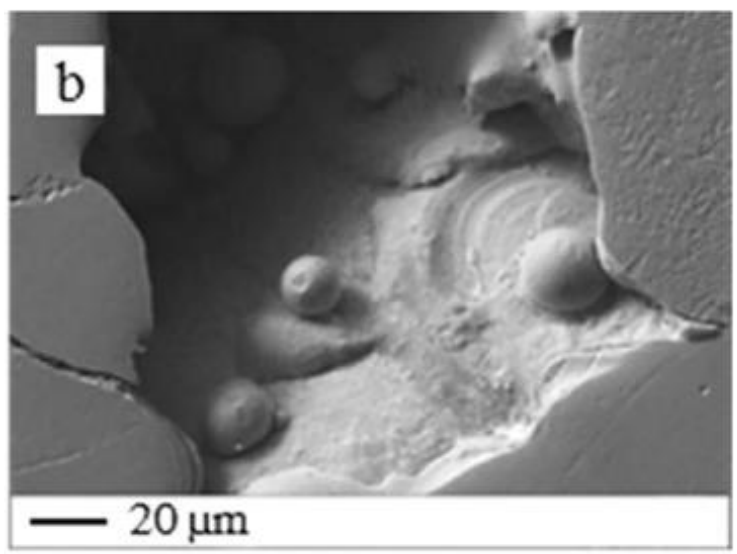

Fig. 6. SEM image of $316 \mathrm{~L}$ stainless steel powder incomplete melting (b) High magnification [12].

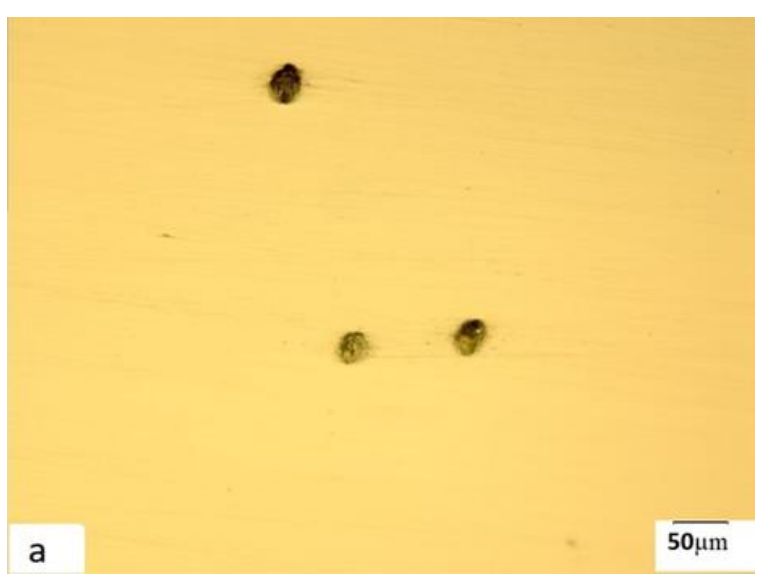

Fig. 7. Optical microscope image of unmelted powder particles before etching. (a) 200x magnification

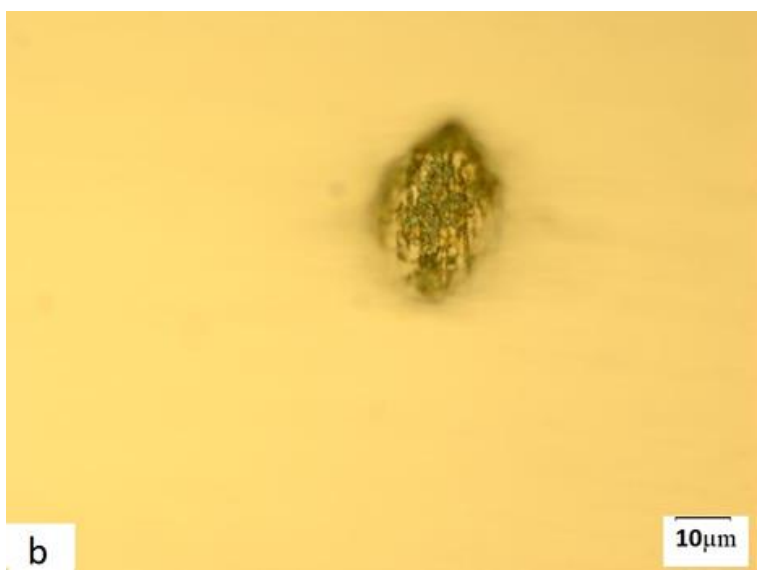

Fig. 7. Optical microscope image of unmelted powder particles before etching (b) 1000x magnification. 
Figures 8 to 11 show the microscopic structure of the sample after etching in two directions, parallel to the print direction and perpendicular to the print direction. In Figure 8, the parallel lines show the field width of the scanning pattern. SEM image in Figure 9 clearly shows the boundary between the scan lines.

Figures 10 and 11 show the microstructure on a plane perpendicular to the print direction at different magnifications. Figure 10 shows the shape of the molten pools and their approximate dimensions. At higher magnifications (Figure 11), rapid melting and solidification of the cellular structure is seen. The different parts of the sample indicate how the complex phases solidify and change during cooling of the molten pool. Such structures have been reported due to rapid cooling leading to nonequilibrium freezing conditions [20].

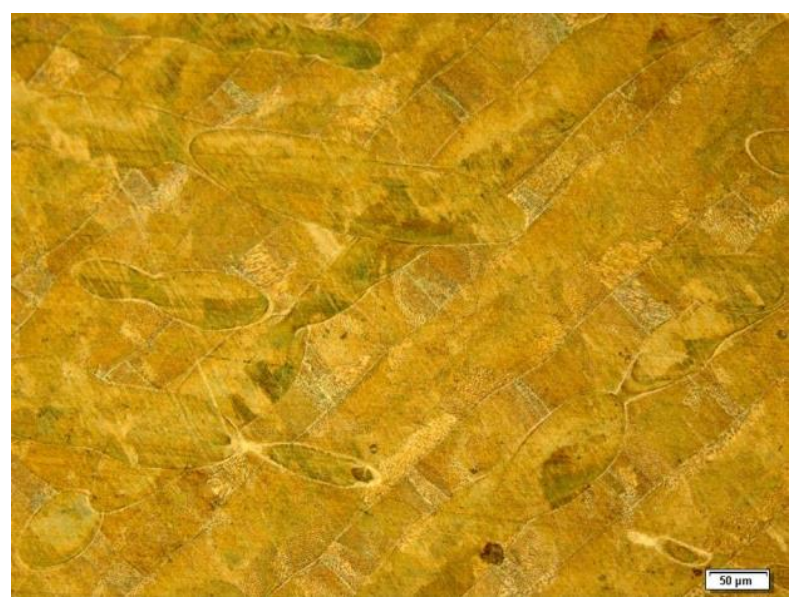

Fig. 8. Light microscope image of scan lines created by a laser beam with 200x magnification, etched with the nitric acid solution.

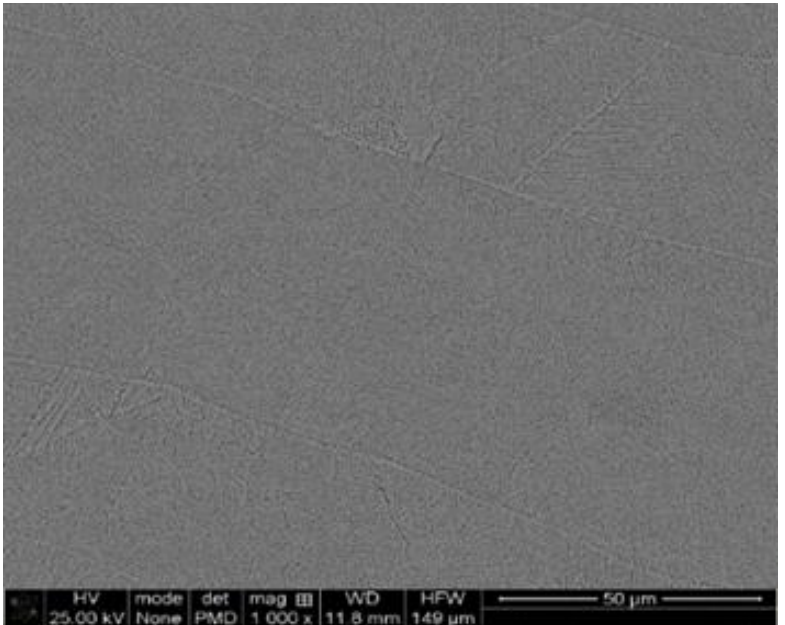

Fig. 9. SEM image of the microscopic structure of the sample in the longitudinal direction with 1000x magnification etched with the nitric acid solution.

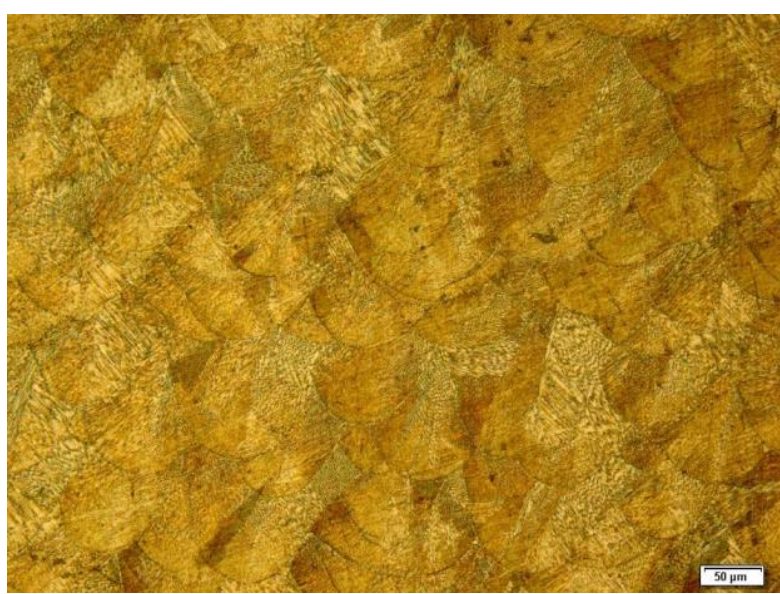

Fig. 10. Optical microscope image of the microstructure of the sample section with 200x magnification, $\mathrm{H}$ with the nitric acid solution.I

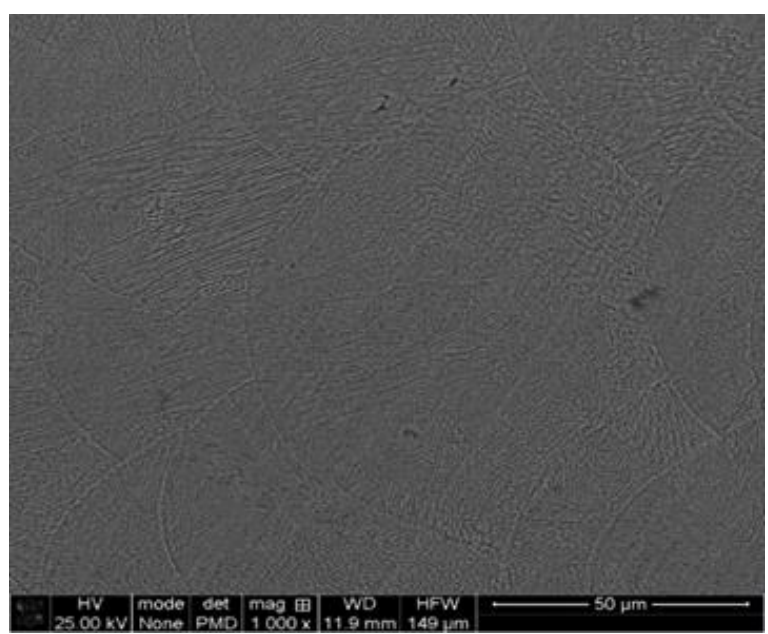

Fig. 11. SEM image of the microscopic structure of the sample section with $1000 x$ magnification, etch with the nitric acid solution. 


\section{B. Worked sample}

Figure 12 shows the microscopic structure of the 316L stainless steel rolled bar at 100 and 1000x magnifications. The sample is in solution annealed condition and has an austenitic structure with a grain size of 8 microns, and is free of impurities and carbides. Equiaxed austenite grains resulting from nucleation and growth can be seen in the annealed sample, which is completely different from the cellular and dendritic structures formed by the melting and solidification process in the sample made with SLM.
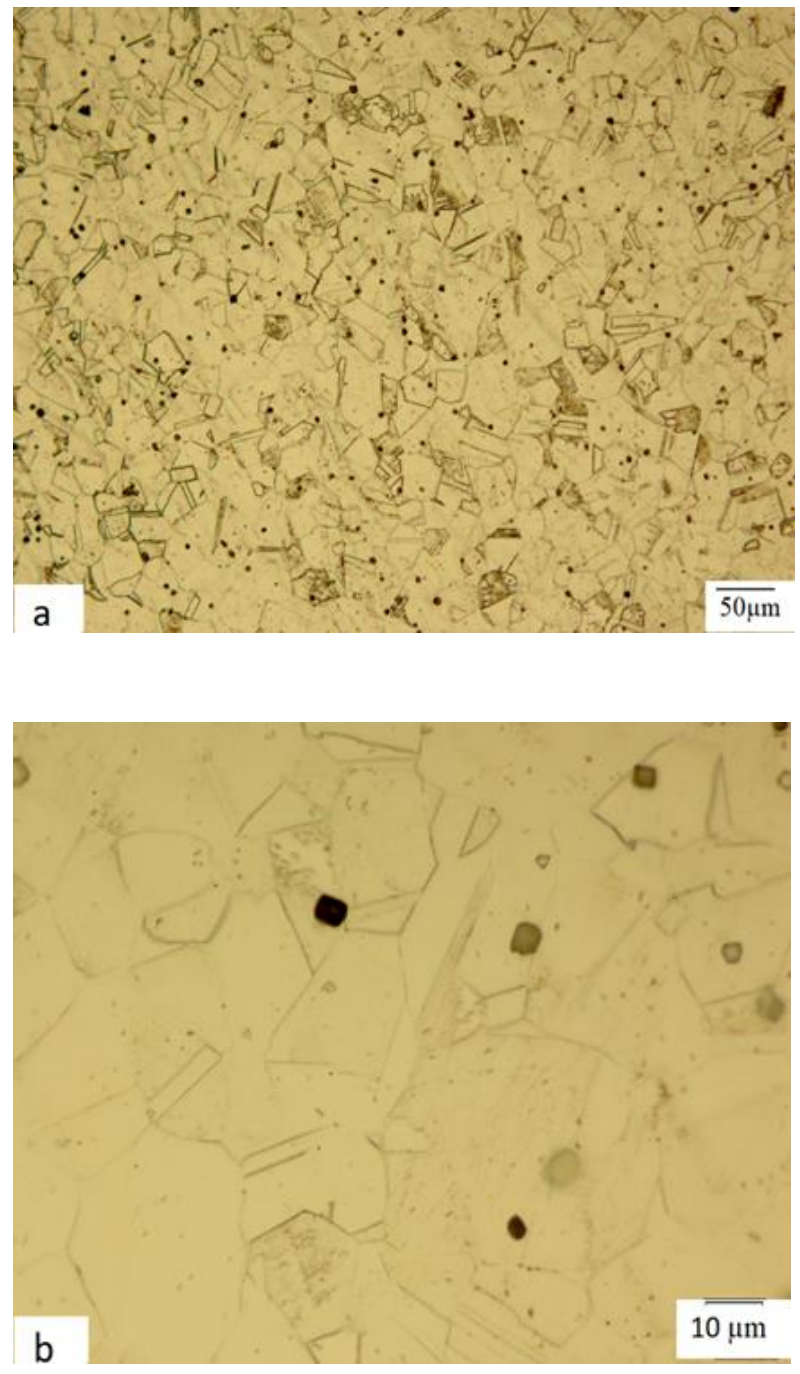

Fig. 12. Microscopic structure of worked bar; (a) 100x magnification; (b) 1000x magnification, soaked in 10\% oxalic acid solution.

\section{Comparison of microscopic structures of SLM, DLD, and worked samples}

Figure 13 shows the microscopic structure of samples made by additive manufacturing with SLM, DLD, and samples made of 316L stainless steel for comparison. As can be seen in this figure, the microscopic structure is similar in the two additive manufacturing methods, with the only difference being the grain size. The reason for the larger grains in the DLD method is the high volume of the melt and consequently the lower solidification rate.
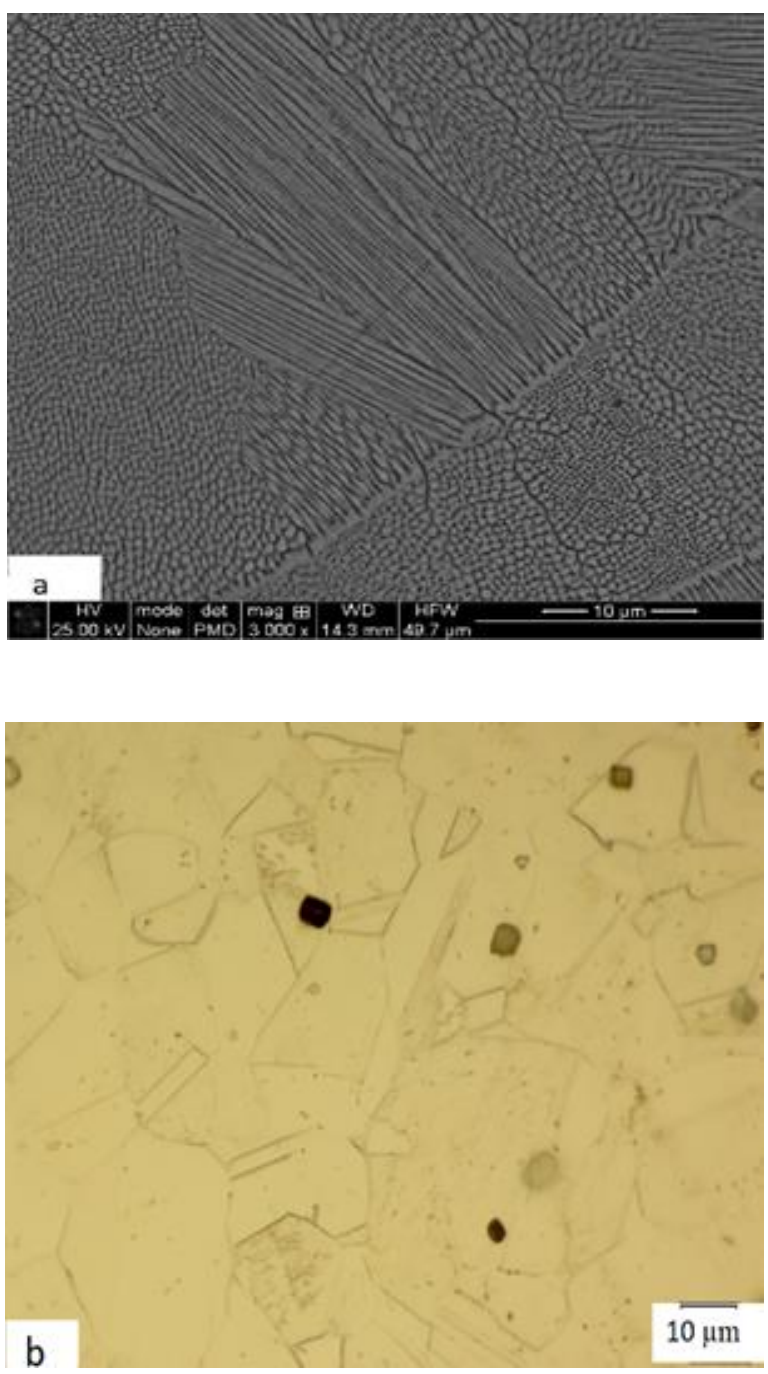


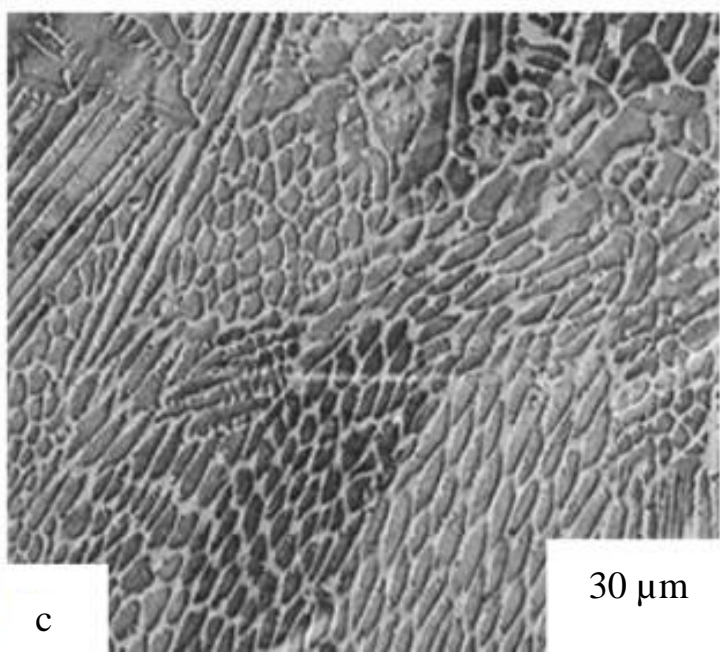

Fig. 13: Microstructure; a) SEM image of a sample made by SLM method etched with the nitric acid solution; b) light microscope image of the worked sample; c) SEM image of the sample made by DLD method etched with $5 \mathrm{ml}$ of nitric acid and $15 \mathrm{ml}$ of hydrochloric acid. [18]

The solidification structure changes from dendritic to cellular in austenitic steels due to the increased cooling rate [20]. In the sample made by the DLD method, the dendritic structure is observed in parts of the sample which is due to the slower cooling rate. In addition, chromium carbide is included in the grain boundary in 316 stainless steel and at low cooling rates. The formation of these carbides reduces the chromium content around the grain boundaries and thus reduces the corrosion resistance. In the sample made by the SLM method in the present study, carbide is not observed due to the high cooling rate. Oxide and carbide impurities are observed in samples made by the DLD method. According to the report of Sklyar et al. [18], the shape of these particles and their dispersion in the structure depends on the power of the input laser.

\section{Mechanical properties}

The mechanical properties obtained from the tensile test as well as the Vickers hardness test are given in Table 3. Mechanical properties and hardness mentioned in the Table 3 are the averages of the values obtained from different samples.

Examination of the results shows that the values obtained for yield stress, tensile strength, and elongation percentage in both SLM and rolled specimens are within the standard range despite the sharp differences in the microscopic structure. There is not much difference in terms of mechanical properties. In the SLM sample, the yield stress is significantly higher than rolled specimen due to rapid solidification and finegrained cell structure and the presence of residual stresses [18]. Tensile strength and elongation percentage are approximately equal in the two samples.

Comparison of SLM and DLD samples shows that yield stress and tensile strength are significantly higher in SLM samples. Microscopic examinations of samples show that they have the same microstructure but with different grain sizes. It can be concluded that higher strength in SLM samples is because of finer grain structure than DLD samples.

The hardness of the sample made by the SLM method is also higher than the other two samples. The molten pool in the SLM process is smaller than the DLD method and therefore has a finer structure, and as a result, this can be the reason for the higher hardness. In general, in the austenitic stainless steels, microhardness is an acceptable measure of the part strength, and the yield stress is linearly related to the microhardness, which depends on the microscopic structure and porosity of the part [14]. 
Table 1

Comparison of mechanical properties of SLM, DLD, and rolled samples.

\begin{tabular}{ccccc} 
Sample & $\begin{array}{c}\text { Yield } \\
\text { Stress } \\
(\mathrm{Mpa})\end{array}$ & $\begin{array}{c}\text { Tensile } \\
\text { Strength } \\
(\mathrm{Mpa})\end{array}$ & $\begin{array}{c}\text { Elongation } \\
(\%)\end{array}$ & $\begin{array}{c}\text { Micro } \\
\text { hardness } \\
(\mathrm{HV})\end{array}$ \\
\hline SLM & 595 & 696 & 34.5 & 252 \\
Rolled & 468 & 688 & 30.9 & 196 \\
$\begin{array}{c}\text { DLD } \\
{[18]}\end{array}$ & 275 & 570 & 50 & 180 \\
\hline
\end{tabular}

\section{CONCLUSION}

This study investigated the mechanical properties and microscopic structure of the $316 \mathrm{~L}$ stainless steel sample produced by the SLM method. The obtained results were compared with the developments related to the rolled bar and also the sample made by the DLD method. In the microscopic images of the SLM sample, the metal layers from the melting and freezing process can be identified as melt pools. The sample's microstructure consists of austenite cellular grins, and the ferrite number measurement shows a completely austenitic structure. The results showed that the strength and hardness of the sample made by the SLM method was higher than the two other samples. The yield stress of the sample made in this research by the SLM method (595 MPa) is 27 percent higher than an annealed bar (468 MPa), and tensile strength is nearly the same for the two samples. According to the ASTM A276 standard, the measured values for yield and tensile strength as well as elongation are within the acceptable range for worked and annealed 316L bars. According to the mentioned standard, elongation of the worked and annealed specimens should be higher than $30 \%$, which in the sample made by the SLM method, this amount is equal to $34.5 \%$. The microscopic structure of the sample made by the DLD method is similar to the sample made in this study. Still, it has lower strength and higher elongation, which can be predicted due to the thicker layers created during melting and consequently lower solidification rate. In terms of possible defects such as cavities due to discontinuity or incomplete melting of powder particles, the sample produced by the SLM method is almost free of these defects, which indicates that the process variables are selected in the appropriate ranges. Overall, the SLM incremental fabrication process to produce $316 \mathrm{~L}$ stainless steel parts is reliable in terms of mechanical properties.

\section{REFERENCES}

1. B. Zhang, Y. Li and Q. Bai, Defect Formation Mechanisms in Selective Laser Melting: A Review, Chin. J. Mech. Eng. 30: pp. 515-527, (2017).

2. T.S. Srivatsan, T.S. Sudarshan, Additive MAnufActuring Innovations, Advances, and Applications, Taylor and Francis group, 2016

3. L. Thijs et al. A study of the microstructural evolution during selective laser melting of $\mathrm{Ti}-$ 6Al-4V, Acta Materialia. 58: pp. 3303-3312, (2010).

4. H. Khalid Rafi, Thomas L. Starr and Brent E. Stucker, A comparison of the tensile, fatigue, and fracture behavior of Ti-6Al-4V and 15-5 $\mathrm{PH}$ stainless steel parts made by selective laser melting, Int J Adv Manuf Technol. 69: pp. 1299-1309, (2013).

5. Luke N. Carter, Moataz M. Attallah and Roger C. Reed, Laser powder bed fabrication of nickel-base superalloys: influence of parameters; characterisation, quantification and mitigation of cracking, In 12th International Symposium on Superalloys, Pennsylvania, (USA, 2012).

6. Q. Jia, D. Gu, Selective laser melting additive manufacturing of Inconel 718 superalloy parts: Densification, microstructure and properties, Journal of Alloys and Compounds. 585: pp. 713-721, (2014). 
7. Jiang Bi et al. Densification, microstructure and mechanical properties of an Al-14.1Mg-0.47Si$0.31 \mathrm{Sc}-0.17 \mathrm{Zr}$ alloy printed by selective laser melting, Materials Science \& Engineering A, 774: pp. 138931, (2020).

8. Pei Wanga et al. Microstructure and mechanical properties of a heat-treatable $\mathrm{Al}-3.5 \mathrm{Cu}-1.5 \mathrm{Mg}$ $1 \mathrm{Si}$ alloy produced by selective laser melting, Materials Science \& Engineering A, 711: pp. 562-570, (2018).

9. P.Wang et al. Microstructure and mechanical properties of $\mathrm{Al}-\mathrm{Cu}$ alloys fabricated by selective laser melting of powder mixtures, Journal of Alloys and Compounds, 735: pp. 2263-2266, (2018).

10. Ruidi Li et al. 316L Stainless Steel with Gradient Porosity Fabricated by Selective Laser Melting, Journal of Materials Engineering and Performance, 19: pp. 666-671, (2010).

11. I. Yadroitsev et al. Single-track formation in selective laser melting of metal powders, Journal of Materials Processing Technology, 210: pp. 1624-1631, (2010).

12. E. Liverani et al. Effect of selective laser melting (SLM) process parameters on microstructure and mechanical properties of $316 \mathrm{~L}$ austenitic stainless steel, Journal of Materials Processing Technology, 249: pp. 255-263, (2017).

13. Taban Larimian et al. Effect of energy density and scanning strategy on densification, microstructure and mechanical properties of 316L stainless steel processed via selective laser melting, Materials Science and Engineering: A, 770: pp. 138455, (2020).
14. Jiangwei Liu et al. Effect of scanning speed on the microstructure and mechanical behavior of 316L stainless steel fabricated by selective laser melting, Materials \& Design. 186: pp. 108355, (2020).

15. J. A. Cherry et al. Investigation into the effect of process parameters on microstructural and physical properties of 316L stainless steel parts by selective laser melting, The International Journal of Advanced Manufacturing Technology. 76(5): pp. 869-879, (2015).

16. Shi Wentian et al. Properties of $316 \mathrm{~L}$ formed by a $400 \mathrm{~W}$ power laser Selective Laser melting with $250 \mu \mathrm{m}$ layer thickness, Powder Technology. 360: pp. 151-164, (2020).

17. G. Miranda et al. Predictive models for physical and mechanical properties of 316L stainless steel produced by selective laser melting, Materials Science and Engineering: A, 657: pp. 43-56, (2016).

18. M. O. Sklyar et al. Microstructure of $316 \mathrm{~L}$ stainless steel components produced by direct laser deposition, Steel in Translation. 46: pp. 883-887, (2016).

19. L. Hitzler, M. Merkel, A Review of Metal Fabricated with Laser- and Powder-Bed Based Additive Manufacturing Techniques: Process,Nomenclature, Materials, Achievable Properties, and its Utilization in the Medical Sector. Advanced engineering materials, (2018).

20. D. Wang, et al. Investigation of crystal growth mechanism during selective laser melting and mechanical property characterization of $316 \mathrm{~L}$, Materials and Design, 100: pp. 291-299, (2016).

\section{How to cite this article}

A. Sazgar, V. Gholizadeh, J. Sherafati, Mechanical properties of 316L stainless steel samples fabricated by selective laser melting and comparison with other manufacturing methods, Journal of Nuclear Science and Applications 2 (1): 8-17 (2022), DOI: $10.24200 /$ jon.2022.1009 